\title{
ESCOLA PARQUE: NOTAS SOBRE A PROPOSTA DE ANÍSIO TEIXEIRA PARA O ENSINO BÁSICO NO BRASIL
}

\author{
Sandra Regina Cassol CARBELLO ${ }^{1}$ \\ Ricardo RIBEIRO ${ }^{2}$
}

RESUMO: Este artigo versa sobre a Escola Parque, proposta elaborada por Anísio Teixeira para organizar o ensino básico no Brasil. Trata-se de um estudo bibliográfico, ancorado em textos produzidos pelo próprio autor e por pesquisadores que se dedicaram ao seu legado. Os registros mostram que a proposta da Escola Parque era um ensaio, audacioso e inovador, para organizar uma política para o ensino primário no Brasil. Foi eximiamente planejada e destacava-se nos aspectos arquitetônico e pedagógico. A experiência da Escola Parque mostrou que é possível ofertar uma educação pública de qualidade e, para tanto, é fundamental compromisso político e sólida formação docente.

PALAVRAS-CHAVE: Escola pública. Centro Educacional Carneiro Ribeiro. Política educacional.

\section{INTRODUÇÃO}

Esta pesquisa volta-se para o legado de Anísio Teixeira, sua proposta para a organização do ensino básico brasileiro e as dificuldades encontradas para efetivá-la como política pública. A escolha desse autor justifica-se pela notoriedade de suas contribuições para a educação. Sua produção deriva de estudos aprofundados e legitimados por ampla experiência na área. Entre outras atividades, Anísio Teixeira atuou na docência, no planejamento e na administração educacional. Seus textos parecem descrever quadros contemporâneos e fundamentam as ações que vislumbram educação de qualidade para todos.

Com intuito de debater a organização do ensino básico, lançamos um olhar exploratório sobre a proposta do Centro Educacional Carneiro Ribeiro, ou Escola Parque, como ficou conhecida. Seu projeto foi pensado para ser transformado em uma política para a educação básica brasileira na década de 1950. Contudo, oscilações políticas e econômicas emperraram sua exequibilidade e ampliação. Posteriormente, alguns projetos educacionais lançados em governos estaduais e até mesmo no governo

\footnotetext{
${ }^{1}$ Doutoranda em Educação Escolar - UNESP - Universidade Estadual Paulista. Faculdade de Ciências e Letras - Pós-graduação em Educação Escolar. Araraquara - SP - Brasil. 14800-901. UEM - Universidade Estadual de Maringá - Departamento de Fundamentos da Educação. Maringá - PR - Brasil. 87020-900 sandra.cassol@gmail.com

${ }^{2}$ UNESP - Universidade Estadual Paulista. Faculdade de Ciências e Letras. Araraquara - SP - Brasil. 14800-901 - despertarosol@gmail.com
} 
federal, na década de 1990, retomaram parcialmente as ideias vanguardistas deste ícone do pensamento educacional brasileiro.

Para discorrer sobre as nuanças de sua proposta, organizamos este texto em duas partes. Na primeira, sinalizamos os questionamentos que nos acompanharam desde as primeiras leituras de suas obras: o que era a Escola Parque? Como surgiu a ideia para esta escola? Qual era sua proposta pedagógica? Na segunda parte do texto, lançamos notas para pensar a organização do ensino básico no Brasil a partir do seguinte questionamento: quais as dificuldades para a Escola Parque se confirmar como uma política pública para a educação básica? Ansiamos que as notas aqui apresentadas possam instigar a leitura deste autor e a tessitura de outros textos que contribuam com o debate sobre a organização do ensino no Brasil.

\section{A ESCOLA PARQUE: UMA PROPOSTA PARA O ENSINO BÁSICO}

Esta primeira parte do texto está didaticamente organizada a partir de três questões que nos aproximaram do legado de Anísio Teixeira: o que era a Escola Parque? Como surgiu a ideia para esta escola? Qual era sua proposta pedagógica? Para respondê-las, recorremos às obras do autor, de seus interlocutores e aos documentos disponibilizados na "Biblioteca Virtual Anísio Teixeira".3 A partir destas leituras, podemos afirmar que a Escola Parque era uma proposta de educação integral que vislumbrava oferecer educação de qualidade para todas as crianças e adolescentes, em especial, às em situação de abandono.

O projeto desta escola atentava-se para o aprendizado das disciplinas convencionais e previa espaços adequados para integração e socialização dos alunos, preparando-os para o trabalho e para o exercício da cidadania. Preocupava-se, também, com os aspectos de saúde, cuidando da alimentação, higiene, prática esportiva e artística. Para Almeida (2001, p.128) a Escola Parque foi pensada "[...] com uma dinâmica e uma estrutura que lembravam uma universidade mirim, a ser desdobrada em outros locais da cidade de Salvador e do interior da Bahia, para acompanhar o processo de urbanização e a incipiente industrialização que se instalava.”

Em seu discurso, na inauguração da escola, Anísio Teixeira anuncia o que fora vislumbrado para a instituição:

\footnotetext{
${ }^{3}$ Disponível em: <www.bvanisioteixeira.ufba.br>
} 
Desejamos dar, de novo, à escola primária, o seu dia letivo completo. Desejamos dar-lhe os seus cinco anos de curso. E desejamos dar-lhe seu programa completo de leitura, aritmética e escrita, e mais ciências físicas e sociais, e mais artes industriais, desenho, música, dança e educação física. Além disso, desejamos que a escola eduque, forme hábitos, forme atitudes, cultive aspirações, prepare, realmente, a criança para a sua civilização - esta civilização tão difícil por ser uma civilização técnica e industrial e ainda mais difícil e complexa por estar em mutação permanente. E, além disso, desejamos que a escola dê saúde e alimento à criança, visto não ser possível educá-la no grau de desnutrição e abandono em que vive. (TEIXEIRA, 1959, s/p).

Fortalecer o ensino primário e oferecer educação de qualidade em período integral era o objetivo da Escola Parque. O funcionamento era como um semi-internato, recebendo os alunos às 7h30min e devolvendo-os às famílias às 16h30min. Havia também uma projeção de internato para crianças abandonadas, porém, não chegou a ser executado.

O inusitado é que todo o esboço para essa proposta proveio de um desafio, lançado justamente, para resolver o problema da infância abandonada. Este desafio foi ordenado por Otávio Mangabeira, governador da Bahia (1947-1951), no momento em que convidou Anísio Teixeira para assumir a Secretaria de Educação e Saúde do Estado. Era a segunda vez que Teixeira ocupava um cargo público na educação baiana.

A primeira vez que assumiu o comando da educação foi em 1924, quando ocupou o cargo de Inspetor Geral do Ensino da Bahia e se deparou com uma situação caótica para administrar. Segundo Lima $(1978$, p.44) “[...] O jovem titular da Inspetoria do Ensino encontrara uma organização pedagógica rotineira e pobre, 600 escolas elementares isoladas e apenas 1 grupo escolar custeados pelo Estado e cerca de 500 escolas municipais". Nunes (2010) contribui com a descrição do cenário que Anísio Teixeira encontrou:

As poucas escolas em funcionamento estavam concentradas em Salvador, localizadas em antigas residências, muitas em ruínas. Era generalizado o costume de o professor custear, com seus próprios recursos, o aluguel da sala ou do prédio em que instalava as "cadeiras". O governo não oferecia mobiliário escolar, nem o professor a adquiria. Cabia ao aluno fornecer cadeiras e mesas improvisadas com barricas, caixotes, pequenos bancos de tábua, tripeças estreitas e mal equilibradas, cadeiras encouradas ou tecidas a junco. Anísio chegou a presenciar que era comum os estudantes escreverem no chão, estirados de bruços sobre papéis de jornal ou, então, fazerem seus exercícios de joelhos, ao redor de bancos ou à volta das cadeiras. (NUNES, 2010, p.17). 
Abreu (1960, p.32), por sua vez, apresenta alguns excertos de documento elaborado por Anísio Teixeira intitulado "Sugestões para a reorganização progressiva do sistema educacional baiano", neste documento expôs a situação precária que queria reverter: “[...] em mil crianças em idade escolar, apenas duzentas frequentam alguma escola; apenas trinta concluem o curso primário elementar; apenas sete obtêm alguma educação secundária e apenas duas têm os benefícios da educação superior." Para enfrentar a situação propôs uma reforma na educação baiana que promovesse "[...] um grande movimento de reorganização, que firmasse uma concepção legítima de escola primária, estabelecesse uma ampla e universal difusão desse ensino e prestigiasse, dando-lhe a dignidade de direito, o professor primário." (TEIXEIRA apud ABREU, 1960, p.21).

Contudo, seus planos foram interrompidos. Em 1929, em razão da dificuldade para sensibilizar o novo governador baiano a realizar suas propostas educacionais, demitiu-se da Inspetoria de Ensino e dedicou-se ao magistério em Salvador. Em 1931, assumiu a Inspetoria de Ensino do Distrito Federal e realizou ampla reforma no sistema público, criando uma rede municipal que se estendia do ensino básico à universidade. Em razão de perseguições políticas advindas do governo de Getúlio Vargas se refugiou no interior da Bahia e dedicou-se a outras atividades.

O convite de Otávio Mangabeira para retornar à vida pública e solucionar o problema da infância abandonada, aconteceu dezoito anos após a primeira gestão. Neste segundo momento, retomou o plano de edificações escolares que havia pensado para resolver os problemas já identificados na Bahia. Intencionava construir unidades para o ensino primário e Centros Regionais de Educação no interior do Estado e escolas de ensino integral na capital. Eram ações que buscavam solução “[...] para o problema do atendimento escolar em prédios escolares que permitissem substituir as aulas realizadas em salas acanhadas e nas residências das professoras, criando, assim, condições para o funcionamento de escolas em tempo integral.” (ALMEIDA, 2001, p.129).

As escolas de tempo integral foram pensadas para resolver a questão da infância abandonada, contudo, para Anísio Teixeira este problema era bem mais abrangente. No discurso de inauguração da Escola Parque, retomou a ordem que recebeu do governador Mangabeira e afirmou: “[...] entre nós, quase toda a infância, com exceção de filhos de famílias abastadas, podia ser considerada abandonada”. O abandono em casa era caracterizado pela ausência de um lar que educasse. Em relação à escola: “[...] se, aparentemente, tinham escolas, na realidade não as tinham, pois as mesmas haviam 
passado a simples casas em que as crianças eram recebidas por sessões de poucas horas, para um ensino deficiente e improvisado." (TEIXEIRA, 1959, s/p).

Para atender as crianças e adolescentes ofertando ensino de qualidade, Anísio Teixeira esboçou o projeto da Escola Parque, solução encontrada para os problemas da capital baiana. Reuniu, então, um grupo de profissionais para pensar o projeto arquitetônico e pedagógico para o funcionamento desta proposta vanguardista de ensino no Brasil. Segundo Almeida (2001, p.127) “[...] a cidade já construída exigia outra modalidade de grupo escolar, provocando a imaginação de um sistema especial de escolas designadas Escola-classe e Escola Parque". Assim nasceu o Centro Educacional Carneiro Ribeiro, mais conhecido como Escola Parque.

Clarice Nunes (2009) sintetiza o projeto:

O projeto de construção do Centro comportava quatro escolas-classe de nível primário para mil alunos cada, com funcionamento em dois turnos; uma escola parque, com sete pavilhões destinados às práticas educativas, onde os alunos completavam sua educação no turno alternado ao da classe. Aos alunos do centro era oferecido um dia completo de permanência em ambiente educativo. (NUNES, 2009, p.125).

Como funcionava esta escola? Qual era a sua proposta pedagógica? Para atingir seus objetivos a escola foi organizada em dois setores: o da instrução e o da educação. No setor de instrução, “[...] manter-se-ia o trabalho convencional da classe, o ensino de leitura, escrita e aritmética e mais ciências físicas e sociais”. O setor de educação concentraria a força da escola ativa, desenvolvendo "[...] atividades socializantes, a educação artística, o trabalho manual e as artes industriais e a educação física." (TEIXEIRA, 1959, s/p).

O dia escolar das crianças era dividido em dois períodos: o da Escola-classe e, no período oposto, o da Escola Parque. Na Escola-classe, formada por um conjunto de 12 salas de aula, mantinha-se o sentido preparatório da escola convencional, ou o ensino das letras e ciências, com os conteúdos típicos das disciplinas. Na Escola Parque, formada por um conjunto de atividades artísticas, esportivas, de preparação para o trabalho, de estudo e fruição, inovava-se com os princípios da educação moderna. Nela,

[...] predomina o sentido de atividade completa, com as suas fases de preparo e de consumação, devendo o aluno exercer em sua totalidade o senso de responsabilidade e ação prática, seja no trabalho, que não é um exercício mas a fatura de algo completo e de valor utilitário, seja 
nos jogos e na recreação, seja nas atividades sociais, seja no teatro ou nas salas de música e dança, seja na biblioteca, que não é só de estudo mas de leitura e de fruição dos bens do espírito. (TEIXEIRA, 1994, p.163).

Nunes (2009, p.126) cita algumas das atividades desenvolvidas no turno da Escola Parque, por alunos que eram agrupados por idade ou preferências:

- artes aplicadas (desenho, modelagem e cerâmica, escultura em madeira, cartonagem e encadernação, metal, couro, alfaiataria, bordados, bijuterias, tapeçaria, confecção de brinquedos flexíveis, tecelagem, cestaria, flores) no Setor de Trabalho;

- jogos, recreação e ginástica no Setor de Educação Física e Recreação;

- grêmio, jornal, rádio-escola, banco e loja no Setor Socializante;

- música instrumental, canto, dança e teatro no Setor Artístico; leitura, estudo e pesquisas no setor de Extensão Cultural e Biblioteca.

O objetivo destas atividades era oferecer aos alunos experiências da vida em sociedade. Almeida (2001) retoma os princípios da proposta e sinaliza que era importante preparar os alunos para os embates da vida social, para isso, pretendia-se construir uma réplica da sociedade na vida escolar. Em texto sobre a Escola Parque o autor explica:

\begin{abstract}
A organização da escola, pela forma desejada, daria ao aluno a oportunidade de participar, como membro da comunidade escolar, de um conjunto rico e diversificado de experiências, em que se sentiria, o estudante na escola-classe, o trabalhador, nas oficinas de atividades industriais, o cidadão, nas atividades sociais, o esportista, no ginásio, o artista no teatro e nas demais atividades de arte, pois todas essas atividades podiam e deviam ser desenvolvidas partindo experiência atual das crianças, para os planejamentos elaborados com sua plena participação e depois executados por elas próprias. (TEIXEIRA, 1967, $\mathrm{s} / \mathrm{p})$.
\end{abstract}

Hermes Lima (1978, p.152) registrou o seguinte depoimento sobre a oportunidade que teve de visitar o Centro em pleno funcionamento: “[...] Era uma coisa diferente e emocionante. A disciplina casava-se a uma autonomia consciente de movimentos. Ali estava um modelo de escola primária que poderia disseminar-se pelo país adaptado às circunstâncias locais".

Em seus registros Almeida (2001, p.131) dimensiona os espaços utilizados na Escola Parque: "O setor recreativo ou de educação física, numa área de $2.775 \mathrm{~m}^{2}$, é constituído de um campo gramado de esporte, campo de basquete, de voleibol, em área 
coberta, 120 banheiros com ducha, cantina e salas para reunião e guarda do material". A autora lança o olhar para o setor artístico e assim o descreve: “[...] compreendendo as atividades de teatro, música e dança, [...] dispõe de um grande auditório semicircular, com palco giratório e capacidade para 5.000 pessoas".

Com relação ao setor socializante, afirma que era composto de banco, jornal, rádio, grêmio e loja. Este setor “[...] era organizado e administrado pelos alunos com a intenção de possibilitar o desenvolvimento das atividades de comunicação e de integração na comunidade escolar." (ALMEIDA, 2001, p.132). Para atingir essas dimensões e integralizar a construção do que fora planejado e inaugurado em 1950, foram necessários 12 anos. O teatro e o pavilhão das atividades sociais foram entregues somente em 1962, antes disso as atividades artísticas e educação física aconteciam ao ar livre. Segundo Nunes (2009) a construção das instalações físicas foram dadas por encerradas em 1964.

Com esses breves apontamentos sobre a Escola Parque, encerramos a primeira parte deste texto e lançamos notas para pensar a organização do ensino básico no Brasil a partir do seguinte questionamento:

\section{QUAIS AS DIFICULDADES PARA A PROPOSTA DA ESCOLA PARQUE SE CONFIRMAR COMO UMA POLÍTICA PÚBLICA DE ENSINO BÁSICO?}

O sonho de Anísio Teixeira era tornar possível o acesso a uma educação de qualidade para todo cidadão brasileiro conquistar uma vida melhor. Contudo, o projeto de educação integral que vislumbrou para o ensino básico foi considerado ambicioso e caro demais para se tornar uma política pública de educação no Brasil. A primeira dificuldade enfrentada para confirmar a proposta da Escola Parque como uma política pública para o ensino básico no Brasil foi seu custo. Para tal crítica, Anísio respondeu: “[...] É custoso e caro porque são custosos e caros os objetivos a que visa. Não se pode fazer educação barata - como não se pode fazer guerra barata.” (TEIXEIRA, 1959). Para os que julgaram o projeto como estapafúrdio e visionário, ele argumentou:

Não é visionário, é modesto. O começo que hoje inauguramos é modestíssimo: representa apenas um terço do que virá a ser o Centro completo. Custará, não apenas os sete mil contos que custaram estes três grupos escolares, mas alguns quinze mil mais. Além disto, será um centro apenas para 4.000 das 40.000 crianças que teremos, no mínimo, de abrigar nas escolas públicas desta nossa cidade. Deveremos possuir, e já não só este, como mais 9 centros iguais a este. Tudo isso pode parecer absurdo, entretanto, muito mais absurdo 
será marcharmos para o caos, para a desagregação e para o desaparecimento. E de nada menos estamos ameaçados. (TEIXEIRA, 1959).

Segundo Almeida (2001, p.126) Anísio Teixeira advertia que não era um plano visionário, mas sim “[...] uma proposta que subverta a simplificação destrutiva e a escola improvisada que reduzem a educação a poucas horas de instrução, impedindo o brasileiro de acreditar que a escola eduque". Para Nunes (2009, p.130) o que distingue a proposta de Anísio Teixeira “[...] é sua concepção de que a educação é um direito civil que está na base da autonomia de sujeitos históricos individuais e coletivos". Segundo o autor, a educação brasileira funciona intencionalmente para não atingir a todos, é seletiva e corrobora na estratificação social, constituindo-se como um privilégio. Na ótica do autor é necessário caminhar para a perspectiva da educação como direito, ela sim, rompe com as amarras sociais denunciadas que estão arraigadas desde séculos. Contudo, este caminho ainda está por ser trilhado, pois para Anísio Teixeira (1994, p.97):

Toda a nossa educação, hoje, é uma educação por decreto, uma educação que, para valer, somente precisa de ser "legal", isto é, "oficial" ou "oficializada". É pela lei que a escola primária de três ou quatro turnos é igual à escola primária completa, que o ginásio particular ou público, sem professores nem condições para funcionar, é igual aos melhores ginásios do país, que a escola superior improvisada, sem prédica nem professores, é igual a algumas grandes e sérias escolas superiores do país.

Na defesa dessa escola que daria à grande massa de trabalhadores uma educação de qualidade Anísio Teixeira (1994) argumentou que a finalidade do ensino primário é habilitar os homens ao trabalho nas suas formas mais comuns e para isso não pode haver uma escola qualquer. É necessário organizá-la de maneira primorosa. Consciente das dificuldades que enfrentaria para manter e expandir seu modelo de escola, evidenciou, em discurso, a preocupação com a qualidade docente para realizar o trabalho: "A maior dificuldade da educação primária, que, por sua natureza, é uma educação universal, é a de se obter um professor primário que possa atender a todos os requisitos de cultura e aptidão para um ensino tão vasto e tão diversificado" (TEIXEIRA, 1959).

Diante disso, afirma que as Escolas Classe teriam os professores primários comuns e a Escola Parque teria professores “[...] especializados de música, de dança, de 
atividades dramáticas, de artes industriais, de desenho, de biblioteca, de educação física, recreação e jogos”. Prossegue o autor:

Em vez de um pequenino gênio para tudo isto, muitos professores diferenciados em dotes e aptidões para a realização da tarefa sem dúvida tremenda de formar e educar a infância nos seus aspectos fundamentais de cultura intelectual, social, artística e vocacional. (TEIXEIRA, 1959, s/p).

Para superar a dificuldade indicada, foram pensadas estratégias para recrutar, mobilizar e capacitar professores. Segundo Nunes (2009, p.125) os professores foram recrutados na capital baiana e no interior. “[...] Passaram por cursos de aperfeiçoamento no Centro Regional de Pesquisas Educacionais da Bahia, no Curso de Artes Industriais do Senai, no Rio de Janeiro, na Divisão de Aperfeiçoamento do Magistério do Centro Regional de Pesquisas Educacionais de Belo Horizonte, [...]”. O envolvimento dos docentes na proposta foi crucial para seu êxito.

Em 1967, Anísio registrou que a experiência foi exitosa, pois "correu o mundo" como exemplo de algo novo no campo educacional, graças ao compromisso e trabalho dos docentes envolvidos. Assevera que: "Não houve para essa experiência nem auxílio nem assistência técnica estrangeira de qualquer natureza. Os professores são todos nossos e os que tiveram a oportunidade de aperfeiçoamento, aperfeiçoaram-se aqui, no Brasil” (TEIXEIRA, 1967). Assinala que o sucesso da experiência aconteceu graças ao conhecimento da diretora e a dedicação dos docentes:

[...] um corpo de professores admiráveis realizou, em silêncio, uma experiência nova, que mereceu o respeito de quantos dela puderam tomar conhecimento, e que aí está sob a vista de todos nós, para mostrar que podemos reconstruir a escola primária, por nós mesmos, desde que nos deem as condições para isto. (TEIXEIRA, 1967).

O registro evidencia a sensibilidade e a atenção com o trabalho da equipe envolvida na realização deste projeto que comprova que é possível ofertar educação de qualidade para todos. Lima $(1978$, p.54) revela o perfil cativante que esteve à frente desta proposta:

Sempre insatisfeito, máquina de pensar e fazer, fascinado pela descoberta de caminhos, a rotina não o amansava nem permitia que a tranquilidade burocrática estagnasse a administração. Estrito no cumprimento dos deveres, exigente nas tarefas do serviço, sabia, 
entretanto, criar em torno de sua liderança um ambiente de franqueza, colaboração e mesmo devoção. Sua inteligência tinha, na verdade, o dom de fascinar.

Em linhas gerais, a Escola Parque foi uma audaciosa proposta para promover o ensino básico. Para Fávero (2001) o segmento mais importante da educação para Anísio Teixeira era o ensino primário e sugere que, talvez por isso, a Escola Parque passou a ser a obra norteadora de toda uma política educacional. Circunscrevia-se assim, um projeto de educação para ser estendido ao país.

Posteriormente, as ideias de Anísio Teixeira foram retomadas em distintas propostas para a educação integral no Brasil. Segundo Nunes (2009, p.130): “O Centro Educacional Carneiro Ribeiro serviu de âncora simbólica para diversos projetos que governos das mais diversas tendências político-ideológicas tentaram implantar”. Como exemplos a autora cita os Centros Integrados de Educação Pública, popularmente conhecidos pela sigla Cieps, que foram desenvolvidos no Rio de Janeiro, no governo de Leonel Brizola. Cita também os Centros Integrados de Atendimento à Infância, os Ciacs, amplamente divulgados no governo do presidente Fernando Collor, na década de 1990. "Pretendeu-se dar continuidade ao modelo de educação integral implantado por Anísio Teixeira, mas essas e outras iniciativas pouco ou quase nada têm a ver com a concepção que alimentou a iniciativa original” (NUNES, 2009, p.130).

Ainda segundo a autora, a concepção do Centro Educacional Carneiro Ribeiro “[...] esteve na base da organização do sistema escolar de Brasília, [...] fazia parte da sua proposta de um plano diretor de educação do governo federal para todo o País" (NUNES, 2009, p.121). No registro de Anísio Teixeira (1961): “O plano de construções escolares para Brasília obedeceu ao propósito de abrir oportunidade para a Capital federal oferecer à nação um conjunto de escolas que pudessem constituir exemplo e demonstração para o sistema educacional do país".

Nunes (2009, p.129) enfatiza que as propostas de Anísio Teixeira sempre tiveram a generosidade de uma visão de conjunto: “[...] A sua política nunca foi para uma escola, mas para o sistema de ensino, mesmo que os custos assustassem as autoridades e os grupos políticos com os quais se aliava, mesmo que exigisse um recrutamento antes impensável de profissionais e sua preparação".

Sua concepção pautava-se no princípio da educação obrigatória, gratuita e universal. Na perspectiva defendida por Anísio Teixeira ela só poderia ser ministrada pelo Estado. Em suas palavras: "Impossível deixá-la confiada a particulares, pois estes 
somente podiam oferecê-la aos que tivessem posses (ou a "protegidos") e daí operar antes para perpetuar as desigualdades sociais, que para removê-las". Prossegue o autor:

A escola pública, comum a todos, não seria, assim, o instrumento de benevolência de uma classe dominante, tomada de generosidade ou de medo, mas um direito do povo, sobretudo das classes trabalhadoras, para que, na ordem capitalista, o trabalho (não se trata, com efeito, de nenhuma doutrina socialista, mas do melhor capitalismo) não se conservasse servil, submetido e degradado, mas igual ao capital na consciência de suas reivindicações e dos seus direitos. (TEIXEIRA, 1994, p.81).

A escola pública vislumbrada era compromissada com a qualidade do ensino, com o uso do que havia de mais moderno para educar as crianças. Nunes (2010, p.31) sintetiza a proposta sonhada por Anísio Teixeira: "Uma escola pública com um Ensino Básico de qualidade para todos [...]. Uma escola bonita, moderna, integral em que o trabalho pedagógico apaixona e compromete professores e alunos".

Aos nossos olhos um investimento necessário, afinal para a oferta de educação de qualidade a proposta de uma escola bonita, moderna e integral é básica. Contudo, se comparado ao que temos oferecido à maioria das crianças e adolescentes compreenderemos o porquê foi considerado audacioso. Em outras palavras, o sonho de Anísio Teixeira de ofertar uma educação de qualidade pautado numa política pública consistente ainda é uma utopia.

\section{CONSIDERAÇÕES FINAIS}

Encerramos este texto com um debate que apenas se inicia, enfatizamos duas notas para pensarmos políticas públicas educacionais a partir do legado de Anísio Teixeira. A primeira delas é que educação é um direito e deve ser organizada com qualidade para todos. Esta deve ser uma premissa para o ensino público.

A segunda nota refere-se ao envolvimento dos docentes num projeto educativo. A experiência da Escola Parque reitera que os professores precisam ser bem formados, respeitados e envolvidos na proposta educativa que se vislumbra, mostrou ainda que quando isso acontece os resultados esperados são alcançados. Anísio Teixeira nos ensina que é possível ofertar uma educação de qualidade para todos. Contudo, ressalta que ela não é barata, não pode ser reduzida a uma oferta qualquer, parcial, sem compromisso. 
Em tempo, registramos que retomar o legado de Anísio Teixeira para pensar a educação brasileira na contemporaneidade é fundamental para conhecer nossa trajetória, entender nossas contradições e os desafios para a organização da escola pública compromissada com a aprendizagem dos alunos.

\section{SCHOOL PARK: NOTES ON ANÍSIO TEIXEIRA PROPOSITIONS FOR BASIC EDUCATION IN BRAZIL}

ABSTRACT: This article deals with the Park School, a proposal prepared by AnisioTeixeira to organize basic education in Brazil. This is a bibliographic study, anchored in texts produced by the author himself and researchers who are dedicated to their legacy. Records show that the proposed Park School was an experiment, bold and innovative, to arrange a policy for primary education in Brazil. Was expertly planned and stood out in the architectural and pedagogical aspects. Park School has shown that it is possible to provide a quality public education; political commitment and solid educational training are therefore fundamental.

KEYWORDS: Public school. Educational Center Carneiro Ribeiro. Educational policy.

\section{REFERÊNCIAS}

ABREU, J. Anísio Teixeira e a educação na Bahia. In: AZEVEDO, F. et al. Anísio Teixeira: pensamento e ação: por um grupo de professores e educadores brasileiro. Rio de Janeiro: Civilização Brasileira, 1960. p.1-68. (Retratos do Brasil, v.3).

ALMEIDA, S. B. A Escola Parque da Liberdade, Bahia. In: MONARCHA, C. (Org.). Anísio Teixeira: a obra de uma vida. Rio de Janeiro: DP\&A, 2001. p.125-140.

FÁVERO, M. de L. de A. Anísio Teixeira: construtor da educação pública. In: MONARCHA, C. (Org.). Anísio Teixeira: a obra de uma vida. Rio de Janeiro: DP\&A, 2001. p.49-72.

LIMA, H. Anísio Teixeira: estadista da educação. Rio de Janeiro: Civilização Brasileira, 1978.

NUNES, C. Anísio Teixeira. Recife: Fundação Joaquim Nabuco: Massangana, 2010. (Coleção Educadores).

Centro Educacional Carneiro Ribeiro: concepção e realização de uma experiência de educação integral no Brasil. Em Aberto, Brasília, v.22, n.80, p.121-134, abr. 2009.

TEIXEIRA, A. Educação não é privilégio. 5.ed. Comentada por Marisa Cassim. Rio de Janeiro: Ed. da UFRJ, 1994. 
A Escola Parque da Bahia. Revista Brasileira de Estudos Pedagógicos, Rio de Janeiro, v.47, n.106, p.246-253, abr./jun. 1967. Disponível em:

<www.bvanisioteixeira.ufba.br/artigos/cecr.htm>. Acesso em: 03 nov. 2013.

Plano de construções escolares de Brasília. Revista Brasileira de Estudos

Pedagógicos, Rio de Janeiro, v.35, n.81, p.195-199, jan./mar. 1961. Disponível em:

<www.bvanisioteixeira.ufba.br/artigos/cecr.htm>. Acesso em: 16 abr. 2014.

Centro Educacional Carneiro Ribeiro. Revista Brasileira de Estudos

Pedagógicos, Rio de Janeiro, v.31, n.73, p.78-84, jan./mar. 1959. Transcrição do discurso pronunciado em 1950 pelo Prof. Anísio Teixeira, quando da inauguração do Centro Educacional Carneiro Ribeiro (Escola Parque), na Bahia. Disponível em:

<www.bvanisioteixeira.ufba.br/artigos/cecr.htm>. Acesso em: 03 nov. 2013. 